\title{
FOREST PATHOLOGY IN RELATION TO CANADIAN SILVICULTURE
}

\author{
By J. E. BIER2
}

\author{
Dominion Laboratory of Patbology, Toronto, Ontario
}

\section{INTRODUCTION}

The preparation of a paper on this subject leads immediately into difficulties of definition as to what should or should not be included. In general foresters have varied concepts of the fields included in silviculture and forest pathology. Undoubtedly, much of this has arisen as the result of the administrative and organizational separation of specialized fields of forestry which, in actuality , are inseparable. To introduce the subject some definition is required of the fields involved.

According to Baker ${ }^{3}$ silviculture may be defined as the art and science of growing and reproducing stands of timber on a basis of permanency. Two major phases are included: (1) reproducing the forest, and (2) tending the forest crop after it has been established. In the same text forest pathology is considered to be a phase of forest protection. It is pointed out that tree diseases are combatted by direct attack with the intent of removing the threat entirely. Silviculture, on the other hand, concerns itself with factors such as climate, soil, moisture and light, which, if unfavourable, are so manipulated that they become less unfavourable.

Boyce defines forest pathology as the branch of botanical science which deals with the diseases of forest trees for the purpose of prevention or control. The concept of the term "pathology" includes a wide range in classes of diseases and covers all interferences with the normal functioning of a sound tree, except those caused by fire and insects. Fungi, bacteria, viruses, mistletoes, noxious fumes, and unfavourable environmental and soil conditions are classified as agents of disease. In agriculture the relatively small areas devoted to a single crop and the short rotation permit direct control of disease by spraying, dusting or altering the crop to some more desirable plant. Direct control of disease in the forest is limited because of the large areas involved and the long rotations. The individual tree in a large forest area cannot be considered as other than a commodity of low value, too low in most instances to warrant direct control measures. Therefore, the purpose of forest pathology in Canada is to stress disease prevention rather than control. The incidence and severity of tree diseases are influenced by factors such as forest composition, tree age, soil and climate, and it is the function of the forest pathologist to determine the pathological factors which interfere with the reproduction, growth and yield of a forest area. With this knowledge the forester may apply some silvicultural. treatment which will prevent the abnormal incidence of disease in the future.

1. Contribution No. 1043, Division of Botany and Plant Pathology, Science Service, Department of fgricalture, Ottawa. To be presented at the 42nd annual meeting of the Canadian
Society of Forest Engineers, Sault Ste. Marie, Ontario, October 26-28, 1950.

2. Próncipal Forest Pathologist, Dominion Laboratory of Forest Pathology, 144 Front Street West, Toronto, Ontario.

3. Baker, F. S. Theory and practice of silviculture McGraw-Hill Book Company, Ine. New York 1934

4. Boyce, J. S. Forest pathology. BcGraw-Hill Book Company, Inc., New Xork. 1948. 
In many instances, therefore, some manipulation of the forest may be necessary to prevent serious losses from diseases. With this in mind the close relationship between pathology and silviculture becomes apparent and possibly it would not be wrong to entitle this paper, "Forest pathology as a part of Canadian silviculture".

It is felt that there has been a tendency for investigators in specialized fields of research related to silviculture to become completely absorbed in their respective lines of investigation with the result that the many interrelationships which may occur in a problem have been overlooked. In some instances the application of the results from pathological studies have been limited because of insufficient emphasis being given to soils, climate, and other factors which may predetermine the intensity of a disease in a given locality. On the other hand, long-term silvicultural experiments have been established with much time and effort only to be abandoned later because of a lack of appreciation of the disease relationships which are present in the areas of investigation. Agencies such as the National Research Council and the Ontario Research Foundation which have organized coordinating committees for forest research will provide a definite means of reducing this difficulty.

In the following paragraphs reference will be made to some of the problems under consideration by pathologists in relation to Canadian silviculture.

\section{Pathology in Relation to Natural Reproduction}

As the mature and overmature forests become more depleted greater emphasis is given to the problems of natural regeneration. In many localities regeneration surveys have been undertaken to indicate the species composition and stocking on burned and cut-over areas. Logically, this is the first step in determining what might be expected in the next crop. Comparatively little has been done to establish why reproduction of the desired species is satisfactory in some areas and not in others. Investigations in forest pathology should assist in solving some of these problems.

The problem of natural reproduction in white pine is of considerable importance in Canada. It is generally recognized that white pine regeneration is very poor in the region south and west of Temagami which has produced large volumes of white pine timber for the Province of Ontario. Comparisons are being made of the pathological condition of white pine of a similar age and on similar sites in the Temagami and Mattawa areas. Much more reproduction is present in the Mattawa area. Is it possible that the fumes from the Sudbury Smelters are affecting the successful establishment of pine seedlings in the Temagami area? The absence of white pine reproduction in some areas in the Ottawa Valley has been accredited to the blister rust disease. Systematic surveys over extensive areas during the past three years have demonstrated less than 5 per cent of the seedlings to be affected. There is no evidence that large numbers of seedlings were killed in previous years. The confirmation of these results over a further period should preclude any possibility of blister rust being the primary factor for the lack of successful reproduction in these areas.

The problem of blister rust is of critical importance in the natural reproduction of western white pine in the interior of British Columbia. Regenera- 
tion under open conditions which favour the development of the alternate host, Ribes, is practically 100 per cent affected. The rough topography of the country and the abundance of diseased Ribes would appear to prohibit the application of direct control measures involving the eradication of the alternate host. This has led many to conclude that it will no longer be possible to grow white pine in the interior of British Columbia. A partial cutting in stands of commercial size should provide sufficient light to encourage pine reproduction. At the same time sufficient shade would be present to prohibit the widespread establishment of Ribes, thus preventing the disease to a large extent. Under these conditions it may be possible to continue the growth of white pine in this region. Favourable results are recorded in Idaho for stands of white pine which have been given this type of silvicultural treatment. In such instances the crop is tended in such a way that we may live with a serious disease rather than attempt to control it.

Unsatisfactory regeneration of yellow birch is recorded for the tolerant hardwood types in Eastern Canada. Current research in conjunction with a project on the deterioration of yellow birch in Ontario has revealed a fungus which is universally present in abundance on dead and dying foliage and twigs. Inoculation experiments have proven the parasitism of this organism on the terminal growth of yellow birch. The abundance of this fungus on the leaves and twigs of larger trees would lead one to wonder as to what effect this disease might have on seedling growth and advanced reproduction. Obviously, moisture conditions conducive to infection would be much more favourable on birch growth near the forest floor than in the tops of trees exposed to the sun and wind. Further research may demonstrate that this disease is an important factor in preventing the successful regeneration of yellow birch.

Comparatively little is known of the importance of root diseases in forest trees. Recent studies have shown that certain of the fungi previously regarded as solely causing heartwood decays at the base of mature and overmature timber may develop into aggressive parasites attacking and killing seedlings and young growth. For example, the fungus Corticium galactinum occurs as a common butt rot in mature and overmature pine, spruce and balsam. Examination of the roots of diseased seedlings has demonstrated that this fungus is an active parasite killing the healthy roots. The same situation may apply to the Poria Weirii root rot disease of Douglas fir on the coast of British Columbia. Fungi such as the above occur commonly in the forests which are being cut at the present time. Therefore, the logging slash, snags and roots of diseased trees produce large quantities of inoculum capable of infecting the seedlings and advanced growth on these areas. Further detailed research in pathology is urgently required to determine the effect such fungi have on the regeneration of coniferous trees.

Frequently it has been considered desirable to leave seed trees on a logged area to provide for better reproduction. Often defective and diseased trees are left since they contain no recoverable volume. Sufficient research has been conducted in forest pathology to demonstrate that within a species the individual trees may vary considerably in their susceptibility to a specific disease. For example, the Rbabdocline needle disease of Douglas fir causes severe de- 
foliation on some trees, but is entirely absent on adjacent trees. Again, repeated examinations strongly. suggest that some white pines are resistant to the blister rust disease. Pathologists are only beginning to undertake the large field of research involving disease resistance and susceptibility as related to forest genetics. The results of this work will be of definite value to silvicultural studies concerning natural reproduction.

\section{Pathology in Relation to the Tending of a Forest}

In some stands thinning experiments have been undertaken in an effort to improve the quality and quantity of the final crop. Although the principle of thinnings conforms to sound forest practice, on occasion pathological factors have arised which have interfered seriously with the ultimate value of these intermediate cuttings. For example, some years ago in Ontario experimental thinnings were conducted in aspen stands. Subsequent to the thinning the residual trees suffered abnormal damage from frost and sun scald. The dead tissue and wounds associated with these lesions gave ready access to infection by the fungus Hypoxylon which later girdled and killed the affected trees. In this instance the occurrence of disease was much higher in the dominant and codominant trees on the thinned areas than on the unthinned controls. Immature stands of Douglas fir on the coast of British Columbia are subject to considerable loss from a root disease caused by the fungus Poria Weirii. The trees are killed in patches which gradually increase in diameter. A recognition of the symptoms and potential damage from this disease would be necessary before conducting thinning operations in second-growth Douglas fir. Otherwise, the volume removed in the thinning together with the trees killed by root rot would result in opening the stand to a greater extent than desirable to obtain a satisfactory final crop. The same problem may arise in the thinning of red pine plantations in Ontario which are infected by Armillaria mellea, a fungus causing a root disease which kills trees in patches.

A knowledge of the symptoms and nature of tree diseases is essential to all foresters engaged in the operation of marking trees for removal in the partial cutting of a stand. Pathologists will serve a very useful function in supplying the pertinent information. Frequently it is considered that disease is restricted to the more suppressed trees in a stand. However, many diseases such as white pine blister rust attack the most vigorous trees. Partially cut stands of white pine have been examined in which an appreciable number of the trees of commercial size left were fatally infected with blister rust. Such trees would be killed and their volume lost before a second cut would be made. In these instances the stem cankers were located at a considerable distance from the ground and would easily escape notice unless a careful examination were made.

Prior consideration should be given to factors such as disease in all longterm experiments in silviculture which. involve the establishment of permanent sample areas for the investigation of growth and yield. On occasion much time and effort have been spent on such work which later had to be abandoned because of a lack of knowledge of the disease relationships. The importance of disease in this work becomes evident when on the re-examination of sample areas up to 35 per cent of the volume on the plots is lost over a period of 15 
years. This was the case in 40-year-old Douglas fir affected by Poria Weirii root rot on the coast of British Columbia. Some of the plots were located in centres of infection for this disease. The problem of root rot in Douglas fir would appear to be more far-reaching than the killing of groups of trees. The openings caused by the disease are becoming filled with western hemlock and western red cedar with the result that the stand composition may change to a Douglas fir-hemlock-cedar type rather than pure Douglas fir.

Experimental pruning has been undertaken to improve the quality of the basal logs in crop trees. Evidence has been obtained to demonstrate that unless extreme care is taken in the pruning operations disease factors may arise which will destroy the value of the pruned trees. For example, some years ago extensive pruning was carried out in immature Douglas fir in Oregon. Later the basal logs of many pruned trees became infected by a wood-destroying fungus which ordinarily occurs only as a top rot in mature and overmature trees. The valuable logs in such trees would be a total loss at the rotation age. It was evident that the abnormal incidence of disease was directly related to pruning wounds which afforded an excellent entrance for infection by the fungus.

It is a well established principle that the loss of commercial wood from the action of wood-destroying fungi increases with the age of the tree. Finally an age is reached when the decay increment exceeds the growth increment, and the area may be regarded as non-productive. In Canada where much of our timber would be classified as mature, one of the most important functions of a forest pathologist is to determine at which age a tree species should be cut to give the maximum returns in sound wood. Since the occurrence and intensity of these diseases may be affected by factors such as soil and climate, the optimum cutting age may vary considerably for the same species in different localities or regions. The cutting age would also vary depending upon the quality of wood desired; for example, within a species, a longer rotation would be required if the crop were to be used for saw logs rather than pulpwood. The results of a considerable number of pathological studies of this character have been published in Canada.

Investigations in forest pathology have a definite place in efforts to improve the utilization practices in overmature timber. Older trees contain varying amounts of decay and the results of pathological research provide foresters with information which assists in determining how far it is economically possible to go in the salvage of sound wood from diseased trees. In addition to the possibility of obtaining a greater recovery per acre the cutting of diseased trees should have a beneficial effect on the subsequent reproduction. It is a common practice to cull and not cut trees which appear defective because of the presence of fungus conks. In some instances the fungus causing a greater part of decay in a species produces conks on the outside which indicate closely the extent of the internal rot column. Seldom does the internal decay extend for an appreciable distance beyond the upper and lower limits of sporophore production. Therefore, the location and extent of the conks on defective trees serve as a reliable indication of the amount of internal decay. This was found to be true for the major decay in Sitka spruce (Fomes Pini) 
on the Queen Charlotte Islands and in aspen poplar (Fomes igniarius) in Ontario. In the above studies it was found that many defective trees had been culled because of the presence of conks in the upper part of the trunks. Analysis of such trees demonstrated that the basal log or logs were sound and would yield substantial amounts of wood of the best quality.

\section{Discussion}

In the foregoing paragraphs reference has been made to some of the functions of forest pathology in relation to Canadian silviculture. Evidence has been presented to indicate that the many specialized fields either forming part of or related to a silvicultural problem are very closely connected and, in fact, should be considered inseparable. A lack in appreciation of any one field may destroy the value of the experiment. It is suggested that a more coordinated effort in the approach to a silvicultural problem which would include specialists in the different fields should lead to sounder research with better possibilities of successful application. 